\title{
The incentive argument for the unionisation of medical workers
}

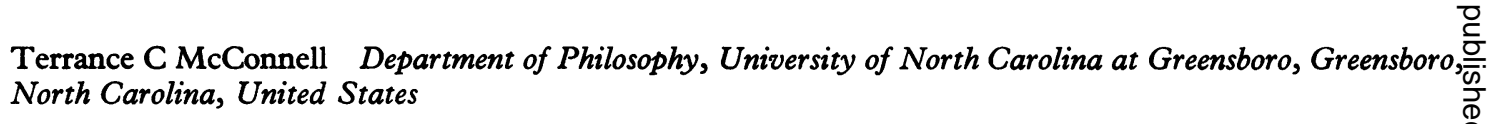

\section{Editor's note}

Unions for medical workers is a much debated subject in the US at present. Dr McConnell looks critically at one of the arguments for the unionisation of medical workers. He analyses many of Dr Marcus's statements on this emotive topic and concludes that he does not think them valid in the campaign for unionisation.

\section{Introduction}

Whenever a country institutes a national health insurance programme, the government in effect becomes the sole purchaser of health care and medical workers often become salaried employees. Many countries have already adopted such programmes. Even in the United States it is claimed that as early as 1975 nearly 25 per cent of physicians were compensated on a salaried basis. ${ }^{1}$ When these things happen, the issues of medical workers' unionising and having the right to strike arise too. In fact, earlier this decade a national survey showed that three out of every five doctors in the United States believed they should unionise. ${ }^{2}$ There is much debate about whether medical workers should have unions and should have the right to withhold their services. Opponents have claimed that unions are 'unprofessional', and in any case since hospitals are non-profit organisations, it is inappropriate for union organisation to take place in that setting.

Recently, however, Dr Sanford Marcus has argued forcefully for the unionisation of physicians. ${ }^{3}$ Many of Marcus' arguments tie the unionisation of medical workers to improved patient care. $\mathrm{He}$ claims, for example, that there are many forces interposing themselves between physicians and their patients. He says that the chief culprits are the insurance industry, the government, and the hospital industry. Their interference is motivated by by a desire to cut medical costs, but their activities threaten to lower the quality of medical care. Physicians' unions can protect the interest of patients by minimising the interference of these outside forces. Marcus also contends that unions are needed in order to influence legislation affecting the medical profession. Only the collective voice of the profession can be heard; individuals are impotent. In addition, Marcus argues that without the power to bargain collectively, medical workers cannot be assured of being paid what they are worth.
Thus in his view it is in the interests of both. physicians and patients if the former can bargain $-\vec{\omega}$ collectively. It should be noted, however, thato Marcus opposes strikes by medical workers. Instead he advocates activities designed to disrupt is the bureaucracy that is trying to interfere with thei medical profession, activities such as refusing to $\vec{\infty}$ fill out forms involved in third-party payments.

\section{A statement of the incentive argument}

The other argument that Marcus advances might bee called the incentive argument (for the unionisation 5 of medical workers). ${ }^{4}$ Marcus believes that the general public will agree with him that medical workers ought to unionise, and to support this claim he states his argument.

After all, no one wants to fly with an airplaneo pilot who's disgruntled because he isn't getting paid enough. Similarly, we can demonstrate that fair compensation for doctors' services will help too increase the chances of high-quality patient care. A dissatisfied corps of doctors cannot reasonably beo expected to remain highly motivated in the face of 3 an actual lowering of their standard of living. ${ }^{5}$

This problem can only be alleviated, Marcus contends, if physicians band together and engage in collective bargaining. My experience has beenthat people have two conflicting reactions to this 3 . argument: on the one hand, there seems to be something persuasive about this line of reasoning on the other hand, there seems to be somethingo wrong with it. What I shall do here is to analyse and critically assess this argument. In so doing I shalp not only try to show what is wrong with the argu ment, but I shall also try to explain why it seems to be plausible. Because socialised medicine is be- $N$ coming more and more a reality and because the incentive argument attempts to appeal to one'so common sense, my task has practical as well aso theoretical importance.

\section{An analysis of the argument}

The central idea underlying the incentive argumentiक is to tie the unionisation of medical workers with $\frac{\mathrm{D}}{\mathrm{D}}$ improved patient care. Of course, many of the $\varrho$ arguments designed to support unionisation for physicians make this same appeal. What is unique about the incentive argument is its claim concerning 
the reason that patients will benefit. If medical workers are permitted to unionise, advocates of this argument reason, patients will indirectly benefit in the following way. A good medical worker is a satisfied one; that is, if medical workers are satisfied with the salary they receive, they will perform their services well. But if they are dissatisfied with the pay they are getting, they will perform their services badly. Why this is called the incentive argument is now clear. What is being asserted is that the effort medical workers put forward and the enthusiasm they have for their job will be proportionate to how satisfied they are. Moreover, their degree of satisfaction will depend on how well paid they are, and we can ensure that physicians and other medical workers will be well paid only if they have the right to bargain collectively. Thus the unionisation of medical workers will guarantee appropriately high salaries and so will result in better patient care.

It is important to understand the theoretical underpinning of this argument. This line of reasoning is utilitarian in nature. The major premiss appeals to the utilitarian principle that one ought to do that action which maximises the good for all affected parties (though in Marcus' argument this premiss is a suppressed one). The minor premiss points to facts which allegedly show that medical workers' unionising is the course of action which maximises the good of the people involved, viz., medical workers and their patients. They both will benefit because patients will receive better care and medical workers will receive a good salary. One could, of course, challenge the utilitarian principle on which this argument is based. However, I shall not do this. My approach will be to meet the advocate of this argument on his own grounds. I shall try to cast doubts on the reasons given in the incentive argument to show that the unionisation of medical workers is necessary to maximise the good.

\section{Critical assessment of the argument}

Is this a good argument? Certainly if adequate health care were otherwise unattainable, then we would extend to physicians the right to unionise. But why, according to Marcus, are adequate health care and the unionisation of medical workers so closely linked? He makes the connection on the basis of several empirical assumptions, on making claims about the incentives and motivation of medical workers. In particular, the defender of the incentive argument asks us to accept a certain psychological portrait of the medical worker when he or she is dispensing his or her services. What Marcus suggests is that monetary concerns motivate the medical worker even at the time he or she is serving his or her patient. He asks us to believe that a medical worker who is making less than he or she thinks is appropriate will become disgruntled and $m$ treat his or her patients sloppily or in a perfunctory $\overrightarrow{\bar{n}}$. manner. The attitude of the person will be this: Why should I work hard and be careful when I am $\Rightarrow$ not being paid enough or treated fairly?

Once one brings this portrait out in the open, one? sees how unrealistic and implausible it is. And one $\frac{\overline{\bar{N}}}{\bar{n}}$ need not be so naive as to think that medical $\frac{\Phi}{\Phi}$ workers are motivated solely by altruistic consider- $\triangle$ ations in order to cast doubt on this account. It is, के of course, true that medical workers are concerned $\vec{\circ}$ about monetary matters. But to claim that financial $\rightarrow$ considerations weigh heavily on their minds at the $\vec{\omega}$ time they are serving their patient is very doubtful. It is more plausible to say that medical workers $-\widehat{\widehat{D}}$ and, for that matter, most professionals - have two or disparate sides or aspects to their personalities, a kind of schizophrenia as it were. For lack of a better description, one might call these aspects the 0 'serving' side and the 'business' side. Surely a doctor performing surgery is not likely to be $\vec{\nabla}$ careless or do a bad job simply because he is $\mathbb{\perp}$ dissatisfied with his salary. As Marcus hismelf $\mathbb{D}$ notes, most doctors are dedicated people, and they often perform important services gratis. ${ }^{\circ}$ Similarly, $\stackrel{\mathbb{C}}{-}$ it is hard to believe that a nurse will not care about $\vec{\varphi}$ her patients simply because she is being underpaid. There is considerable evidence gathered from some o recent interviews which indicates that even among the semi-skilled and unskilled medical workers there is a strong degree of commitment to service. In spite of the fact that these people describe their working $\frac{D}{D}$ conditions as bad and their pay as too low, they show a devotion that is rarely matched by workers in other areas. ${ }^{7}$ This suggests that when medical $\frac{3}{\partial}$ workers are serving their patients, their principal concern is the well-being of those patients and not the financial rewards they will reap. (The same thing, I might add, can be said about the airplane pilots : whom Marcus mentions. They will surely not 3 . endanger the lives of their passengers simply $\delta$ because they are unhappy with their salary.) This is not to say, however, that medical workers are 0 unconcerned about monetary matters. When a medical worker is deciding whether to take a new job offer, certainly a chief consideration will be the pay. And, if a medical worker were negotiating a $\%$ new contract, clearly money would be of paramount $N$ importance. It seems, then, that there are two $\underset{\mathrm{C}}{\mathrm{N}}$ distinct sides to the medical professional, and for $O$ the most part they are unrelated. Thus Marcus' version of the incentive argument fails because it $\frac{\mathscr{D}}{\mathscr{D}}$ rests on a false premiss: money does not play the $\stackrel{?}{+}$ role that he says it does at the time one is dispensing 0 one's services.

\section{Why the argument seems plausible}

Nonetheless there does seem to be some connection between motivation and pay, and that is why there 
seems to be something correct about the incentive argument, or at least a modified version of that argument. The connection is simple enough. If physicians, nurses, and other medical workers are not paid well, good people will not be attracted to these fields. As a result, in the long run patients will suffer. So it is in the interest of all of us to see to it that the various medical professions are sufficiently lucrative to attract the best possible people. In fact, it is often said that it is precisely our failure on this point which has led to there being an excessive number of surgeons and a shortage of primary care physicians or general practitioners. Does granting this show that the incentive argument is correct after all ? It does not. Marcus assumes in his statement of the argument that the only way that physicians can be assured of a satisfactory salary is if they have the power to bargain collectively. Recall that in this context 'satisfactory salary' just means a high enough salary to attract good people. So understood, Marcus' assumption is surely false. At the present time there is no shortage of qualified people seeking admission to medical school; the opposite is the case. This must indicate, according to advocates of the incentive argument themselves, that current salaries are quite satisfactory; the incentive is there. Even if a shortage were to develop, and even if we knew that this were caused by too low a pay scale, the problem could be rectified without giving medical workers the right to have unions. We could simply make the financial rewards of the particular profession great enough so that the best people would again be motivated to enter that field. It seems, then, that we, members of the general public, are sufficiently motivated to see to it that the salary of medical workers is appropriately high.

\section{Conclusion}

As we have seen, Marcus' version of the incentive argument for the unionisation of medical workers is $m$ a utilitarian one. But even if one accepts this $\overrightarrow{\bar{n}}$. utilitarian framework, the argument fails because it rests on the implausible claim that medical workers $\vec{F}$

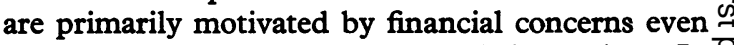
at the time they are dispensing their services. In addition, while it is true that monetary matters play $\frac{\overline{\bar{c}}}{\bar{D}}$ a role in any person's decision about what profession $\vec{\sigma}$ to enter, this alone does not show that the right of $\stackrel{\mathbb{Q}}{2}$ collective bargaining should be extended to medical के workers, as Marcus assumes it does. Such a con- $\vec{\circ}$ clusion would be warranted only if there were no other way to guarantee that the salary of medical $\vec{\omega}$ workers will be high enough, and this is certainly? not the case. Of course, it does not follow from this that medical workers ought not to unionise. I have ir examined only one of the arguments. Whether any of the others succeed is a topic for further dis- $\stackrel{\infty}{N}$ cussion.

\section{References}

'See the editorial statement by Wolfe, S (1975). International journal of health services, 5, 4I.

${ }^{2}$ Urlich, S (1973). Will your appendectomy be per- $\overrightarrow{0}$ formed by a member of the AFL-CIO ? Modern hospital, 121, 63-67.

${ }^{3}$ Marcus, S A (1975). The purpose of unionisation in the medical profession, International journal of health services, 5, 37-42, and Marcus, S A (1975), The time has come to bargain for higher incomes, $\stackrel{\circ}{\Phi}$ Medical economics, 52, 204-214.

'Daniels, N (1978). On the picket line: are doctors' strikes ethical ? Hastings Center Report, 8, 27.

${ }^{5}$ Marcus, The time has come to bargain for higher incomes, 214 , op cit.

'Ibid., 209.

'Ehrenreich, B and Ehrenreich, J (1975). Hospital' workers: class conflicts in the making, International? journal of health services, 5, 44-45. 